\title{
Efeitos da intensidade luminosa sobre a morfo- anatomia foliar de Bouchea fluminensis (Vell.) Mold. (Verbenaceae) e sua importância no controle de qualidade da droga vegetal
}

\author{
Milaneze-Gutierre $^{1 *}$, M. A. ${ }^{1}$; Mello, J. C. P. ${ }^{2}$; Delaporte, R. H. ${ }^{3}$ \\ ${ }^{1}$ Departamento de Biologia, ${ }^{2}$ Departamento de Farmácia e Farmacologia, Universidade Estadual de \\ Maringá, Maringá, PR; ${ }^{3}$ Departamento de Farmácia, Universidade Paranaense, Umuarama, PR.
}

RESUMO: Para a implantação de rigorosos padrões de controle de qualidade das drogas vegetais, além da detecção dos princípios ativos e das metodologias clássicas de microscopia, deve-se também considerar as alterações morfo-anatômicas ocasionadas pelo ambiente, especialmente quando a droga constitui-se de folhas. Neste estudo, foram analisadas as folhas de Bouchea fluminensis cultivadas em pleno sol ou na sombra. As folhas "de sol" são menores do que as "de sombra", com limbo mais ondulado e mais coriáceas ao tato. A análise anatômica revelou espessa cutícula estriada, estômatos anomocíticos em ambas faces, embora raros na face adaxial das folhas de "sombra". Dois tipos de tricomas foram observados, sendo um tector simples com paredes ornamentadas e outro glandular, assim como feixes vasculares colaterais sem tecidos esclerificados, estando os menores envoltos por bainha de células não esclerificadas. A espessura média do mesofilo das folhas "de sol", bem como a altura das células do parênquima paliçádico são significativamente maiores do que nas folhas "de sombra" o que permite diferenciá-las facilmente. A não observância de alterações fotomorfogênicas, nas diversas espécies vegetais utilizadas na forma de droga, pode ocasionar falhas ou dúvidas na identificação das mesmas.

Unitermos: Bouchea fluminensis; Verbenaceae; morfo-anatomia; controle de qualidade.

ABSTRACT: The effect of light intensity on morpho-anatomy of leaves of Bouchea fluminensis (Vell.) Mold. (Verbenaceae) and their importance on the plant drug control quality. In order to establish rigorous quality control standards for plant drugs, in addition to active substances detection and use of classical microscopical methods, the morpho-anatomical changes caused by the environment must be considered, specially when the plant drug are leaves. In this study, leaves of Bouchea fluminensis cultivated in full sun or in shade were analyzed. Sun leaves are smaller than shade leaves, and their blades are more undulating and leathery to the touch. Anatomical analysis revealed a thick striated cuticle with anomocytic stomates on both faces, although few stomates were present on the adaxial face of shade leaves. Two types of hair were observed, one is a simple tector with ornamented walls, and the other is glandular, as well as collateral vascular sheafs without sclerified tissues, the smaller ones surrounded by a sheath of unsclerified cells. The mean thickness of the mesophyll and the height of the palisade parenchyma cells of sun leaves are significantly higher than in shade leaves, which allows them to be easily distinguished. Failure to observe these photomorphogenic changes in plant species may give misleading results in the identification of plant drugs.

Key words: Bouchea fluminensis; Verbenaceae; morpho-anatomy; quality control. 


\section{INTRODUÇÃO}

As plantas medicinais vêm sendo utilizadas há séculos para suprir, muitas vezes, as necessidades de assistência médica primária da população. Nas últimas décadas, o aumento do consumo dessas espécies se deve a fatores, tanto econômicos quanto à procura de uma medicina alternativa. Nota-se, com isto, o incremento e a diversificação dos estudos relacionados com tais plantas. Entretanto, aspectos relevantes e básicos, como a correta identificação das espécies e a disponibilidade de descrições morfo-anatômicas, ainda, são barreiras no controle de adulterações de diversas drogas vegetais, comprometendo a qualidade das mesmas. Dessa maneira, toda a cadeia produtiva fica comprometida, caso a realização do controle de qualidade não siga um rigoroso padrão de análise. Esses fatos têm contribuído para a má qualidade das drogas vegetais, com conseqüente prejuízo para os medicamentos fitoterápicos com elas produzidos.

Nesse contexto, a identificação de fragmentos vegetais secos, muitas vezes na forma rasurada ou de pós, é uma tarefa indispensável àqueles que buscam obter produtos de boa qualidade. Os aspectos morfo-anatômicos dos órgãos e a identificação dos tecidos (parênquimas, colênquimas e tecidos condutores) ou de células características da espécie-alvo (idioblastos, tricomas, esclereídeos) subsidiam tanto a qualidade como a autenticidade da droga vegetal.

Na literatura botânica básica, tais como Esau (1965), Cutter (1986) e Raven et al. (2001) encontram-se descrições de alterações morfo-anatômicas foliares, ocasionadas por fatores ambientais, como a intensidade luminosa que sobre elas incide. Segundo Raven et al. (2001), a luz pode promover efeitos substanciais no desenvolvimento, no tamanho e na espessura das folhas. Em geral, as folhas que se desenvolvem sob alta intensidade luminosa, denominadas folhas "de sol", são menores e mais espessas do que aquelas que permanecem sob baixa intensidade, as folhas "de sombra". Este padrão de alteração pode variar entre as espécies, podendo ser expressivo nas folhas de Chenopodium album L. (YANO; TERASHIMA, 2001) ou não ser estatisticamente significativo, como nas folhas de soja [Glycine max (L.) Merr.] (SERT, 1992). Por outro lado, Dengler (1980) observou que as folhas "de sol" de girassol (Helianthus annuus L.) são maiores e menos espessas do que aquelas que se desenvolveram em locais sombreados.

A espécie vegetal, objeto de estudo deste trabalho, Bouchea fluminensis (Vell.) Mold. é um subarbusto lenhoso, popularmente conhecido no norte do Paraná, como "gervão-falso" ou "falsogervão". Pio Corrêa (1984) também cita as sinonímias populares: "gervão-da-folha-grande", em São Paulo, e "gervão-da-folha-larga", em Minas Gerais. A denominação popular "gervão" é usada para outras espécies da família Verbenaceae, conhecidas em toda a extensão territorial brasileira, resultando deste fato, a grande confusão observada em sua sinonímia científica e, conseqüentemente, na identificação botânica de algumas espécies (COSTA, 1960). São sinonímias de B. fluminensis: Bouchea pseudogervao (A. St-Hil.) Cham., Verbena fluminensis Vell., Verbena pseudogervao A. St. Hil. e Verbena seudogervao A. St. Hil. (MISSOURI BOTANICAL GARDEN, 2003).

Na medicina popular, as folhas e os caules de $B$. fluminensis são utilizados como antiemético e estimulante do aparelho digestivo (PIO CORRÊA, 1984). Estudos farmacológicos comprovaram a atividade antiinflamatória de extratos de folhas (DELAPORTE et al., 2001, 2002). Do ponto de vista químico, vários iridóides já foram isolados desta espécie, como lamiídeo, lamiidosídeo e durantosídeo II (SCHUQUEL et al., 1998).

No entanto, estudos morfológicos ou anatômicos deste gênero são raros, inclusive aqueles que envolvem as alterações provocadas pelos fatores ambientais. Visto que as folhas de Bouchea fluminensis (Vell.) Mold. mostram-se suscetíveis às variações da intensidade luminosa sob as quais se desenvolvem, sendo visualmente distintas, faz-se necessária a caracterização morfoanatômica das mesmas, objetivando a identificação correta desta espécie medicinal e auxiliando no controle de qualidade da droga vegetal.

Rev. Bras. Farmacogn., V. 13, n. 1, jan.-jun. 2003. 


\section{MATERIAL E MÉTODOS}

\section{Material vegetal}

O material botânico (Figura 1A) foi coletado no Horto de Plantas Medicinais da Universidade Paranaense (UNIPAR) e identificado pela Dra. Fátima Regina Salimena-Pires. A exsicata encontrase depositada no Herbário da Universidade Federal de Juiz de Fora (MG) com o número CESJ 30113.

\section{Análise anatômica}

As secções anatômicas, à mão livre, foram preparadas com folhas maduras (quarto e quinto nós) coletadas dos ramos superiores, expostos ao sol pleno (folhas "de sol"), e dos ramos que se desenvolveram sombreados pelos demais (folhas "de sombra"). Os cortes foram corados com azul de astra e safranina (soluções aquosas a 1\%) (KRAUS; ARDUIN, 1997).

Para a avaliação da espessura foliar total e do parênquima paliçádico foram utilizadas dez folhas (coletadas de diversos exemplares) de cada intensidade luminosa, e destas preparadas cinco cortes de cada porção (ápice, meio, bordo e base), totalizando 50 réplicas. As medidas foram obtidas com ocular milimetrada acoplada ao microscópio óptico.

Para as contagens dos estômatos e tricomas foram preparadas cinco réplicas da porção mediana, de ambas as faces e de cada tipo de folha, através da técnica de decalque, utilizando cola instantânea. Foram analisados 10 campos de $1 \mathrm{~mm}^{2}$ por réplica, totalizando 50 contagens. Esta técnica é de aplicação simples e rápida, e compreende em recortar quadrados de aproximadamente $1 \mathrm{~cm}$ de lado, da porção do limbo foliar a ser analisada. Após limpeza das lâminas com etanol ou éter, pinga-se uma pequena gota de cola instantânea sobre a mesma. Imediatamente, coloca-se sobre a cola uma das porções recortadas do limbo. Com auxilio de papel absorvente faz-se leve pressão sobre o material vegetal, o qual, após alguns minutos, é retirado, estando a impressão da epiderme foliar pronta para ser analisada ao microscópio óptico.

As áreas foliares foram obtidas de acordo com a metodologia proposta por Jordão et al., (1988), tendo sido avaliadas 50 folhas de cada intensidade luminosa, as quais foram contornadas com fino traço de lápis sobre papel tipo sulfite com gramatura 90 e, a seguir, recortadas e pesadas em balança analítica. Os pesos obtidos foram comparados com aquele de uma área de $25 \mathrm{~cm}^{2}$ do papel acima citado.

As análises estatísticas foram realizadas através do programa SAS (STATISTICAL ANALYSIS SYSTEM, 1996) versão 6.12, sendo as médias comparadas pelo teste de Tukey.

\section{RESULTADOS E DISCUSSÃO}

As folhas de Bouchea fluminensis são simples, opostas cruzadas, ovaladas de ápice agudo, base decurrente, bordo dentado e ligeiramente pilosas em ambas as faces. Quando frescas, as folhas "de sol" e as "de sombra" podem ser facilmente diferenciadas através de suas texturas, sendo as primeiras mais coriáceas e com limbo mais ondulado do que as "de sombra" (Figura 1B e 1C). As áreas foliares mostraram-se estatisticamente distintas entre as folhas "de sol", cuja área média é de $17 \mathrm{~cm}^{2}$, e as "de sombra", com área média de $27 \mathrm{~cm}^{2}$. Em ambos os tipos de folha, o pecíolo mostra-se canaliculado, embora distintos quanto ao comprimento médio, tendo os das folhas "de sol" $1,25 \mathrm{~cm}$, e as "de sombra" $2,3 \mathrm{~cm}$. 

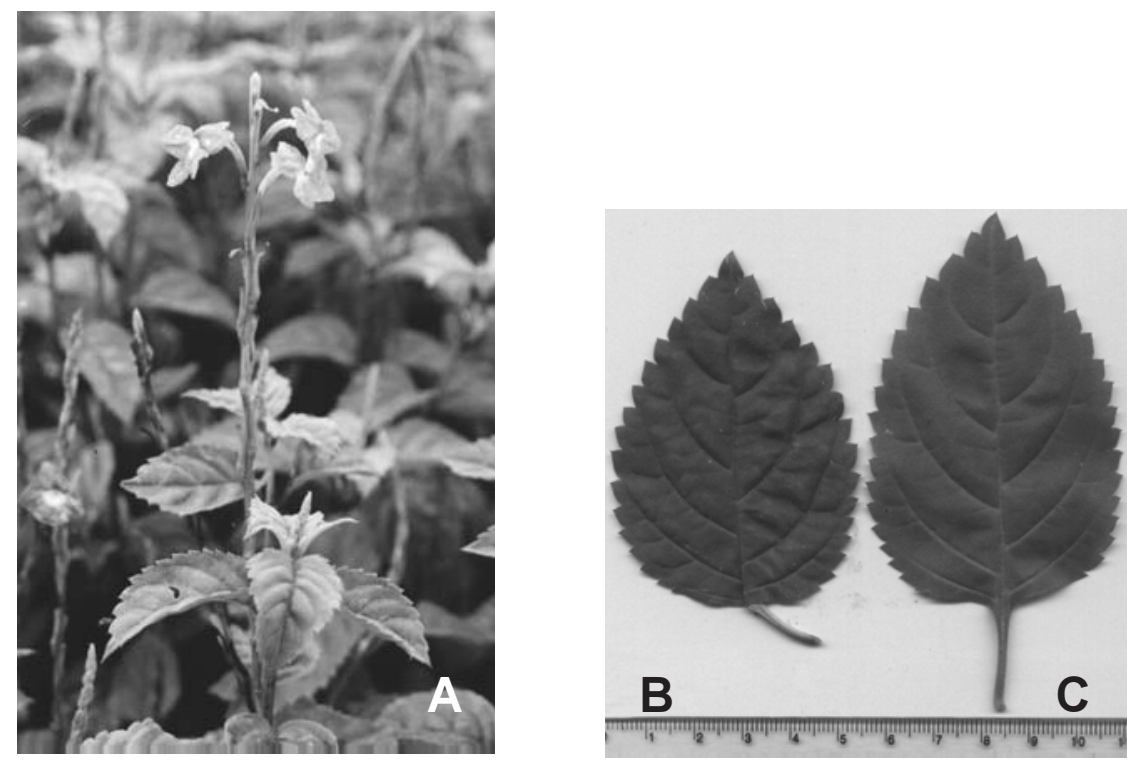

Figura 1. Bouchea fluminensis (Vell.) Mold. (Verbenaceae). (A) Aspecto geral do ramo florido; (B) folha "de sol"; (C) folha "de sombra".

A epiderme foliar de $B$. fluminensis é unisseriada e recoberta por espessa cutícula estriada. Em ambas as faces e condições de luminosidade, as células apresentam formatos irregulares, por vezes alongadas periclinalmente, mas sempre com paredes com expressivas sinuosidades (Figuras 2A e 2B), muito semelhantes às de Clerodendrum splendens $\mathrm{G}$. Don, Stachytarpheta jamaicensis (L.) Vahl e Citharexylum subserratum Sw., analisadas por Inamdar (1969).

A folha é anfiestomática, com estômatos, na maioria das vezes, do tipo anomocítico, ocorrendo com relativa freqüência, também os do tipo diacítico. De acordo com Metcalfe e Chalk (1972), a presença de estômatos em ambas as faces caracteriza algumas espécies de Verbenaceae, como Amasonia, Casselia, Baillonia e muitas espécies de Bouchea, sendo comuns, nestas, os tipos paracítico e diacítico. Na maioria das espécies de Verbenaceae, analisadas por Inamdar (1969), e nas duas espécies de Clerodendrum analisadas por Herman (1998), os estômatos são do tipo diacítico, podendo ocorrer juntamente com outros tipos.

Como anexos epidérmicos ocorrem dois tipos de tricomas. O mais abundante, e apresentando tamanhos diversos, é do tipo tector unisseriado ornamentado, composto normalmente por uma única célula, mas quando sobre a face adaxial da nervura principal (Figuras 2E e 4A) e pecíolo (Figura 5B) podem apresentar-se com duas, ou mais raramente, três ou quatro células. O outro tipo de tricoma observado nas folhas de $B$. fluminensis é do tipo glandular, estando composto por duas células apicais e duas basais (Figuras 2B e 2D). Tricomas semelhantes aos descritos acima foram observados por Bassols e Gurni (2000) nas quatro espécies argentinas de Lippia por eles analisadas, embora os tricomas tectores fossem sempre unicelulares. As câmaras subestomáticas são amplas e, por vezes, comunicam-se com os espaços intercelulares do parênquima esponjoso (Figura 2C). 

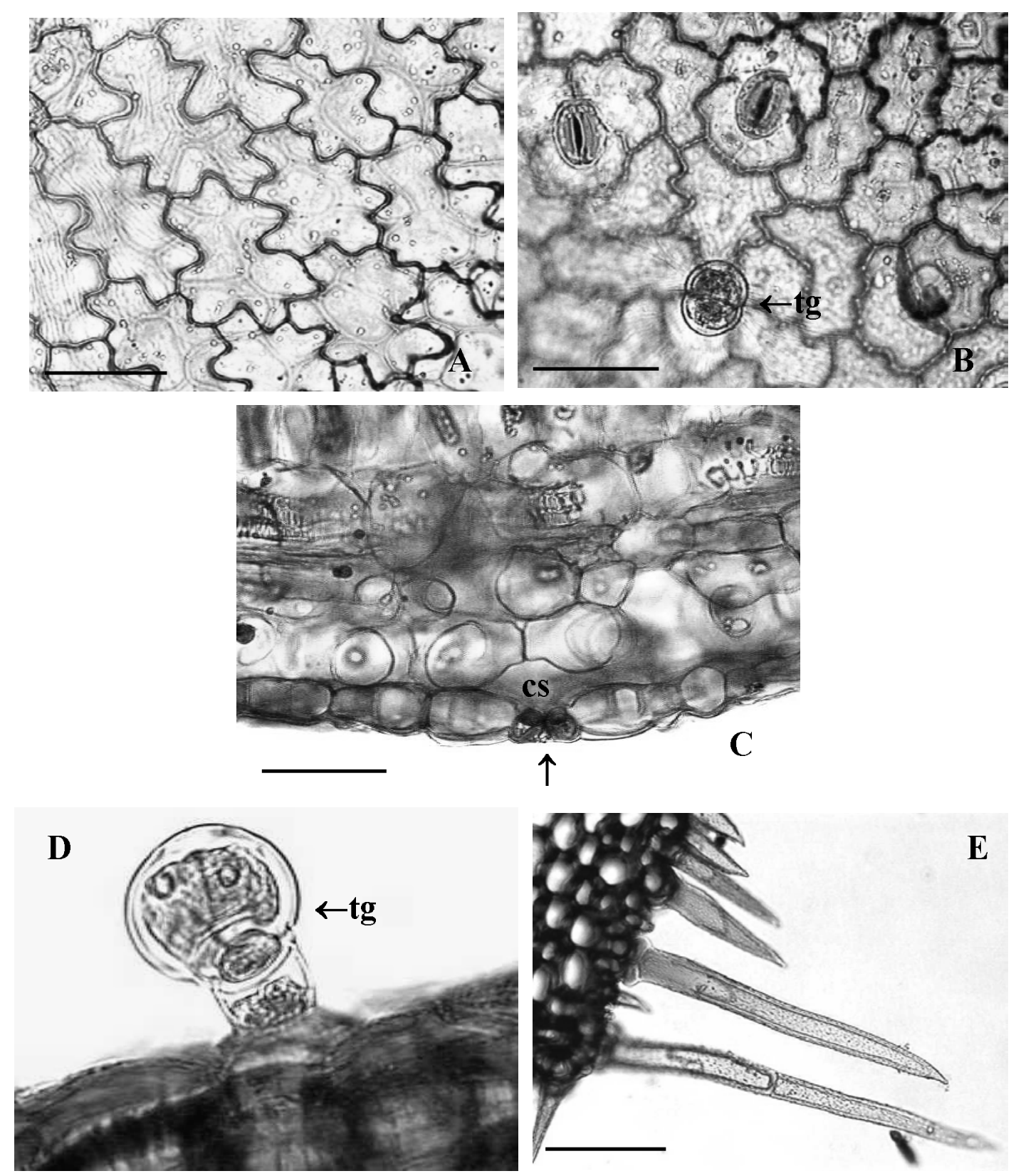

Figura 2: Epiderme foliar de Bouchea fluminensis (Vell.) Mold. (Verbenaceae) e seus anexos. (A) face adaxial; (B) face abaxial; $(C)$ detalhe de um estômato em secção transversal $(\rightarrow)$; (D) tricoma do tipo glandular (tg); (E) tricomas tectores presentes na nervura principal; cs: câmara subestomática. Barra de E: $100 \mu \mathrm{m}$ e as demais $50 \mu \mathrm{m}$.

De acordo com a Tabela 1, ocorrem diferenças estatísticas no número médio de estômatos e de tricomas tectores entre as condições de luminosidade sob as quais as folhas se desenvolveram e, como na maioria das espécies vegetais, também entre ambas as faces foliares. Os números médios mais elevados de estômatos por área, nas folhas "de sol" refletem a pouca expansão celular das demais células epidérmicas, e não a diferenciação de novas unidades estomáticas, como concluíram Knecht e O'Leary (1972). Resultados semelhantes aos observados acima foram obtidos por estes últimos autores nas folhas de feijão (Phaseolus vulgaris L.) e por Van Volkenburgh e Davies (1977), que estudaram folhas de algodão e soja, enquanto que Sert (1992) não obteve 
maior freqüência de tricomas nas folhas de soja [Glycine max (L.) Merrill.], mantidas sob sol pleno, quando comparadas às mantidas em casas de vegetação.

As médias relativamente baixas de estômatos na face adaxial das folhas "de sombra" podem dar a falsa impressão de que estas estruturas não estão presentes nesta face foliar, fato verificado em $62 \%$ dos campos analisados nas folhas "de sombra" e em apenas $24 \%$ das amostras das folhas "de sol".

Tabela 1. Números médios de estômatos e tricomas presentes nas folhas "de sol" e "de sombra" de Bouchea fluminensis (Vell.) Mold. (Verbenaceae).

\begin{tabular}{|c|c|c|c|}
\hline Tipo de folha/face foliar & $\begin{array}{l}\text { Estômatos } \\
\left(\text { em } 1 \mathrm{~mm}^{2}\right)\end{array}$ & $\begin{array}{l}\text { Tricomas tectores } \\
\quad\left(\mathrm{em} 1 \mathrm{~mm}^{2}\right)\end{array}$ & $\begin{array}{c}\text { Tricomas glandulares } \\
\left(\mathrm{em} 1 \mathrm{~mm}^{2}\right)\end{array}$ \\
\hline Folha "de sol"/adaxial & $7,12 \mathrm{c}$ & $7,04 \mathrm{~b}$ & $1,97 \mathrm{bc}$ \\
\hline Folha "de sol"/abaxial & $95,05 \mathrm{a}$ & $13,10 \mathrm{a}$ & $3,62 \mathrm{a}$ \\
\hline Folha "de sombra"/adaxial & $1,35 d$ & $3,31 d$ & $1,45 \mathrm{c}$ \\
\hline Folha "de sombra"/abaxial & $53,32 \mathrm{~b}$ & $5,18 \mathrm{c}$ & $2,77 a b$ \\
\hline
\end{tabular}

Médias seguidas por letras distintas são estatisticamente diferentes pelo teste de Tukey.

As secções transversais das folhas de $B$. fluminensis revelam mesofilo dorsiventral com parênquima paliçádico formado por apenas uma camada de células, mais altas e esguias nas folhas "de sol" do que nas folhas "de sombra" (Figuras 3A e 3B). Nessas últimas ocorrem espaços intercelulares amplos e abundantes, os quais não ocorrem nas folhas "de sol". Em ambos os tipos foliares, o parênquima esponjoso mostra-se formado por células de braços curtos, conferindo-lhe aspecto compactado (Figuras 2C, 3A e 3B). De acordo com Metcalfe e Chalk (1972), nas espécies de Bouchea podem ocorrer apenas uma ou muitas camadas de células no parênquima paliçádico.

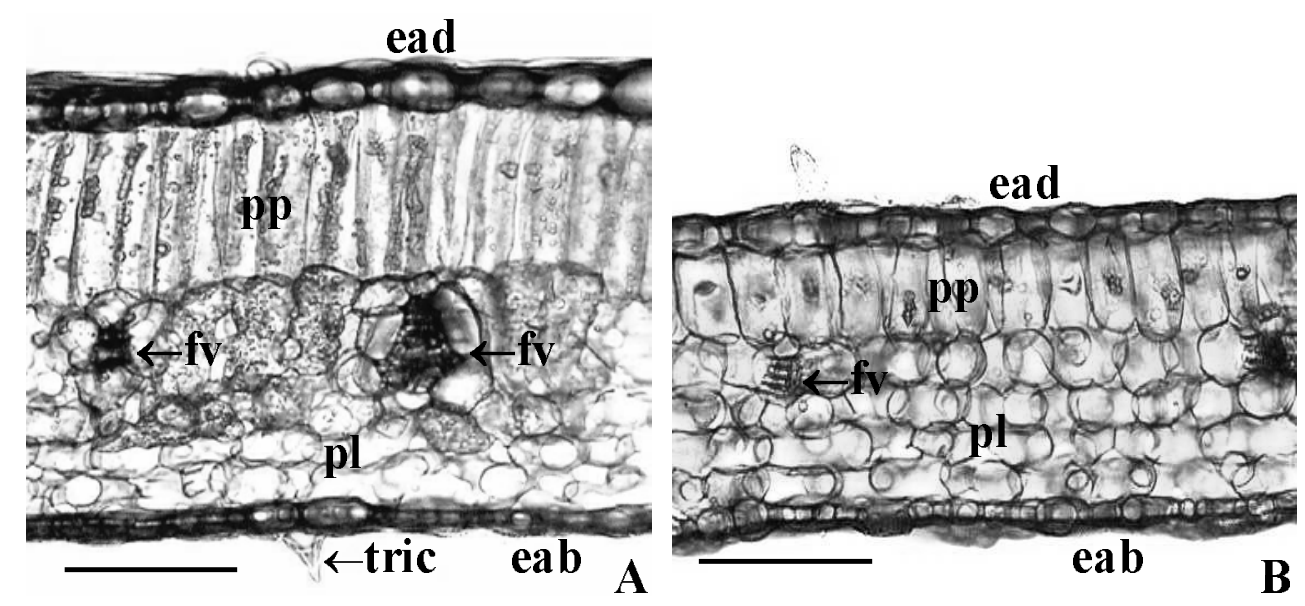

Figura 3. Secções transversais medianas de folhas de Bouchea fluminensis (Vell.) Mold. (Verbenaceae). (A) folha "de sol"; (B) folha "de sombra"; eab: epiderme abaxial; ead: epiderme adaxial; fv: feixe vascular; pl: parênquima esponjoso; pp: parênquima paliçádico; tric: tricoma tector. Barras: $100 \mu \mathrm{m}$. 
Metcalfe e Chalk (1972) citam a ocorrência de mesofilo dorsiventral e isobilateral para espécies da família Verbenaceae, enquanto que Herman (1998) observou ambos os tipos em diferentes espécies de Clerodendrum, e Bassols e Gurni (2000) obtiveram apenas mesofilo isobilateral nas quatro espécies de Lippia analisadas.

De acordo com as condições de luminosidade, sob as quais se desenvolvem, as folhas de $B$. fluminensis mostram diferenças significativas na espessura total do mesofilo, do parênquima paliçádico e, em algumas das porções foliares, também na porcentagem de ocupação deste tecido (Tabela 2).

Tabela 2. Medidas obtidas nas folhas "de sol" e "de sombra" de Bouchea fluminensis (Vell.) Mold. (Verbenaceae) .

\begin{tabular}{|c|c|c|c|c|}
\hline \multicolumn{2}{|c|}{ Tipo de folha/porção foliar } & $\begin{array}{l}\text { Espessura total do } \\
\text { mesofilo (em } \mu \mathrm{m})\end{array}$ & $\begin{array}{c}\text { Espessura do } \\
\text { paliçádico (em } \mu \mathrm{m})\end{array}$ & $\begin{array}{c}\text { \% de ocupação do } \\
\text { paliçádico }\end{array}$ \\
\hline \multirow{4}{*}{$\begin{array}{l}\text { Folha "de } \\
\text { sol" }\end{array}$} & apical & $352,2 \mathrm{a}$ & 147,8 a & $44,58 \mathrm{ab}$ \\
\hline & mediana & $325,8 b$ & $128,0 \mathrm{~b}$ & $42,73 \mathrm{bc}$ \\
\hline & basal & $320,4 \mathrm{~b}$ & $107,4 \mathrm{c}$ & $37,5 \mathrm{~d}$ \\
\hline & bordo & 349,8 a & $153,2 \mathrm{a}$ & 46,35 a \\
\hline \multirow{4}{*}{$\begin{array}{l}\text { Folha "de } \\
\text { sombra" }\end{array}$} & apical & $211,6 \mathrm{~d}$ & $79,2 d$ & $41,27 \quad c$ \\
\hline & mediana & $235,8 \mathrm{c}$ & $74,8 d$ & $36,24 d$ \\
\hline & basal & $209,6 d$ & 60,8 e & $35,78 \quad d$ \\
\hline & bordo & $209,2 d$ & $84,4 \mathrm{~d}$ & $44,57 \mathrm{ab}$ \\
\hline
\end{tabular}

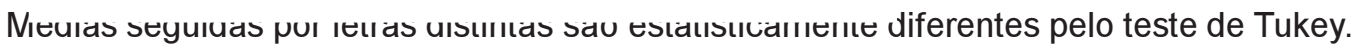

Estas diferenças anatômicas, aliadas às alterações morfológicas presentes na epiderme foliar (Tabela 1), comprovam que as folhas de $B$. fluminensis são susceptíveis às variações de intensidade luminosa. Este fator pode promover modificações na espessura e área foliar, nos espaços intercelulares, no número de camadas do mesofilo e na distribuição dos fotoassimilados, como observado por Fails et al. (1982), Kappel e Flore (1983), Almeida (1985) e Lawlor (1987), caracterizando a plasticidade fenotípica das espécies. Nas espécies estudadas por Fails et al.(1982), Syvertsen e Smiyh (1984) e Nii e Kuriowa (1988) foram observadas maiores proporções de espaços intercelulares no parênquima esponjoso, e Cutter (1986) considera tal fato decorrente da expansão das células do mesofilo, tornando, assim, este parênquima mais difuso. Os estudos de Mc Connel et al. (1984) e de Syvertsen e Smith (1984) revelaram que a intensidade luminosa mais alta favorece o desenvolvimento de folhas mais espessas em Aphelandra squarrosa Nees 'Dania' e em espécies de Citrus, respectivamente.

A nervura principal das folhas de $B$. fluminensis apresenta uma pequena convexidade na face adaxial das porções mediana e basal, onde se concentram colênquima do tipo angular e tricomas (Figura 4A). Na face oposta desta nervura há acentuada convexidade, havendo poucas camadas de colênquima angular dando-lhe sustentação (Figura 4A). O xilema e o floema estão reunidos num único feixe colateral na forma de arco aberto, não havendo elementos esclerificados ao seu redor. De acordo com as Figuras 4B e 4C, as folhas "de sol" podem ser diferenciadas das folhas "de sombra" pela quantidade de elementos condutores presentes na nervura principal, sempre mais numerosos nas primeiras. Quanto aos feixes vasculares de menor calibre, observase que estão envoltos por uma bainha de células parenquimáticas de tamanhos irregulares e não 
esclerificadas (Figura 3A) e, de acordo com Metcalfe e Chalk (1972), essa característica é comum em vários gêneros de Verbenaceae, inclusive em Bouchea.
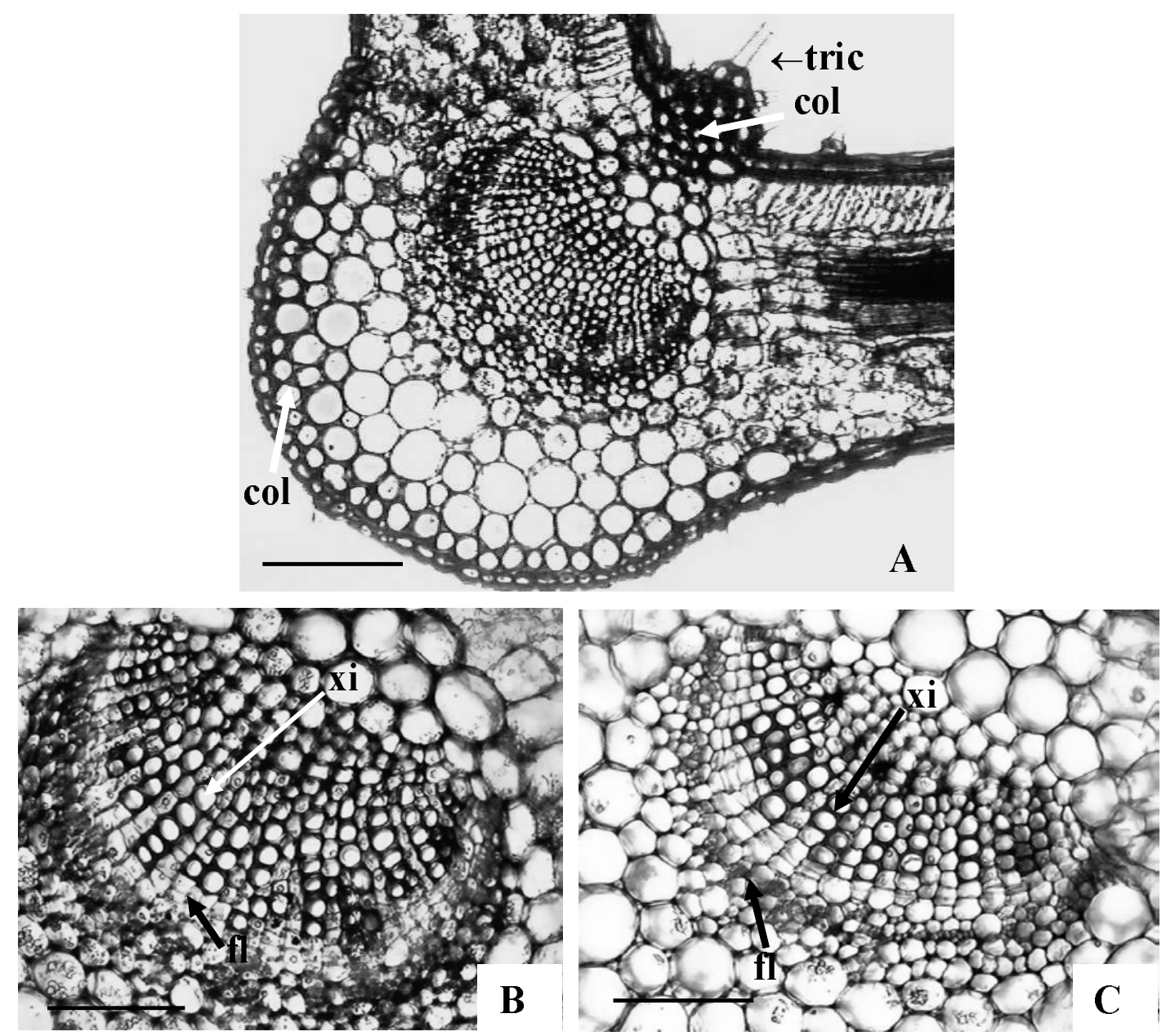

Figura 4. Secções transversais medianas da nervura principal da folha de Bouchea fluminensis (Vell.) Mold. (Verbenaceae). (A) folha "de sol"; (B) detalhe de seu feixe vascular; (C) feixe vascular de uma folha "de sombra"; col: colênquima; fl: floema; tric: tricoma; xi: xilema. Barra de A: $200 \mu \mathrm{m}$ e as demais: $100 \mu \mathrm{m}$.

O pecíolo das folhas de $B$. fluminensis, em secção transversal (Figura 5) mostra convexidade na face adaxial, e onde se concentram tricomas, especialmente os tectores mais longos (Figura 5B). Nesta região adaxial, logo abaixo da epiderme, estão várias camadas de colênquima angular (Figuras $5 \mathrm{~A}$ e $5 \mathrm{~B}$ ), enquanto que no restante da estrutura ocorrem de duas a três camadas (Figuras $5 B$ e $5 C$ ). Nas secções transversais da porção distal do pecíolo (Figuras 5B e 5D) nota-se a presença deste tecido de sustentação no bordo do limbo foliar.

No pecíolo, internamente, encontra-se tecido de preenchimento formado por células de tamanhos diversos e, entre elas, espaços intercelulares relativamente pequenos (Figura $5 \mathrm{C}$ ). $\mathrm{O}$ feixe vascular do pecíolo (Figuras $5 \mathrm{~A}$ e $5 \mathrm{~B}$ ) mostra-se semelhante ao da nervura principal, inclusive quanto ao número de elementos condutores presentes nas folhas "de sol" e "de sombra". Desde a base do pecíolo ocorrem dois pequenos feixes secundários, posicionados lateralmente ao feixe principal. 
Gutschick (1999) afirma que as variações estruturais verificadas nas folhas ocorrem entre indivíduos da mesma espécie e até nele próprio. Tal diversidade é adaptativa, estando sob controle genético, incluindo as respostas relacionadas ao tamanho das folhas e a massa por unidade de área, em resposta à luz ambiente.

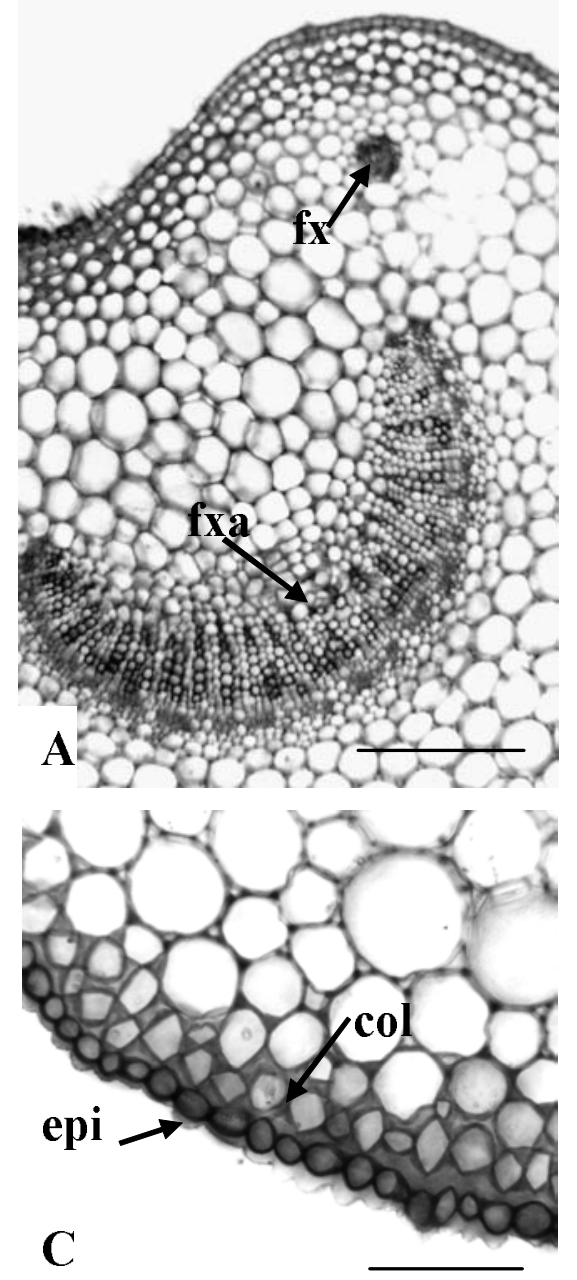

C
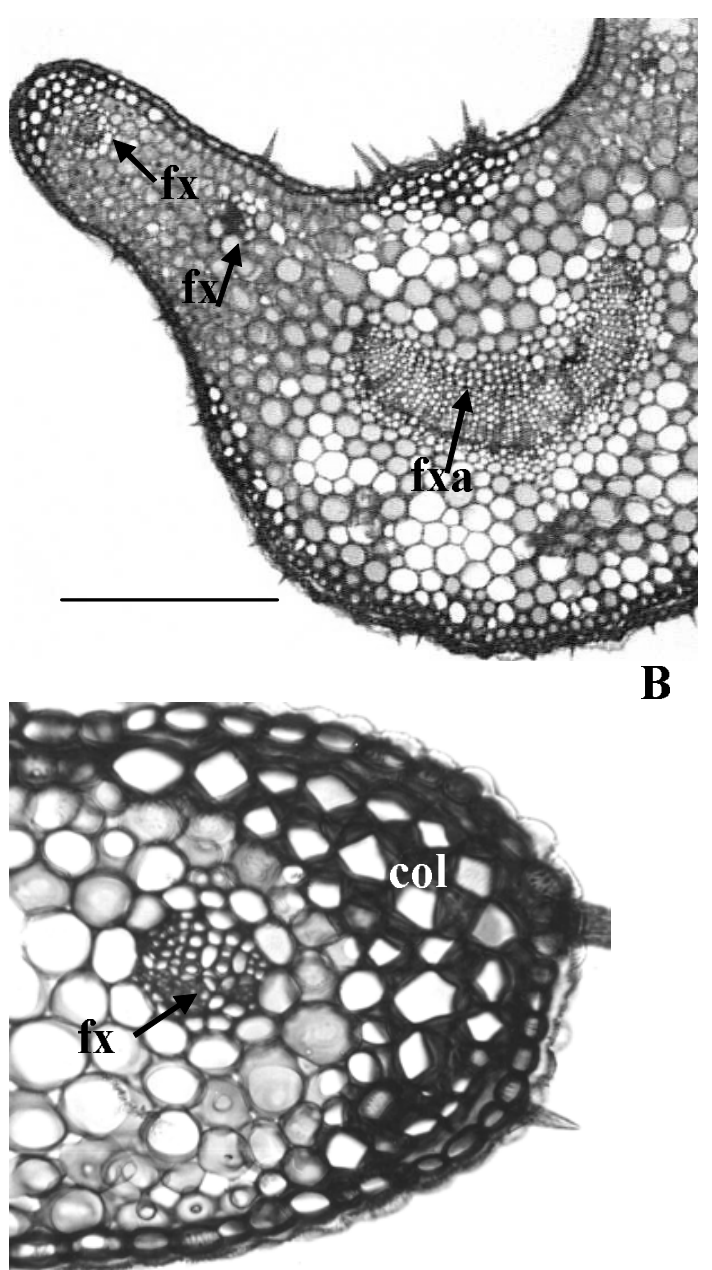

D

Figura 5. Secções transversais do pecíolo de Bouchea fluminensis (Vell.) Mold. (Verbenaceae). (A) porção basal em uma folha "de sombra"; (B) porção distal em uma folha "de sol"; (C) e (D) detalhes do colênquima na face adaxial e no bordo decurrente do limbo, respectivamente; col: colênquima; epi: epiderme; fx: feixe vascular secundário; fxa: feixe vascular em arco. Barras de A e B: $500 \mu \mathrm{m}$ e C e D: $100 \mu \mathrm{m}$.

\section{CONCLUSÕES}

Alterações morfo-anatômicas relacionadas ao meio ambiente, como aquelas ocasionadas pelas variações da intensidade luminosa sobre as folhas, como demonstrado, podem modificar as características macroscópicas e microscópicas, levando a confusões na identificação da espécie ou mesmo à falsa idéia de adulteração. Portanto, variações causadas pelo meio devem ser estudadas de modo a estabelecer, de forma correta e segura, a identificação das plantas medicinais e das drogas vegetais delas derivadas, assegurando a produção de medicamentos fitoterápicos. 


\section{AGRADECIMENTOS}

Agradecemos à Dra. Fátima Regina Salimena-Pires da Universidade Federal de Juiz de Fora (MG) pela identificação botânica da espécie e ao Departamento de Agronomia da Universidade Estadual de Maringá, pela utilização do fotomicroscópio.

\section{REFERÊNCIAS BIBLIOGRÁFICAS}

ALMEIDA, A.A.F. Efeito da radiação solar e do nitrogênio sobre o crescimento, produção e composição química do feijoeiro (Phaseolus vulgaris L. Cv. "Negrito 897"). 1985. 198p. Dissertação (Mestrado em Fisiologia Vegetal). Universidade Federal de Viçosa, Viçosa.

BASSOLS, G.; GURNI, A.A. Comparative anatomical study on argentine species of Lippia known as "poleo". Pharmaceutical Biology, v.38, n. 2, p.120-128, 2000.

COSTA, O. A. Estudo farmacognóstico do gervão. Revista Brasileira de Farmácia, v.51, n.11/12, p.5-24, 1960.

CUTTER, E.G. Anatomia vegetal. Parte 2: Órgãos, experimentos e interpretações. 2. ed. São Paulo: Roca, 1986.

DELAPORTE, R.H., SÁNCHEZ, M.G., GIULIANI, A, CUÉLLAR, C.A.; MELLO, J.C.P. Anti-inflammatory activity and lipid peroxidation inhibition of iridoid lamiide isolated from Bouchea fluminensis (Vell.) Mold. (Verbenaceae). Journal of Ethnopharmacology, v. 82, p.127-130, 2002.

DELAPORTE, R.H.; SÁNCHEZ, M.G.; CUÉLLAR, C.A.; MELLO, J.C.P. Control de calidad y actividad antiinflamatoria de las drogas Alternanthera brasiliana (L.) Kuntze y Bouchea fluminensis (Vell.) Mold. Acta Farmaceutica Bonaerense, v.20, n.1, p. 39-46, 2001.

DENGLER, N.G. Comparative histological basis of sun and shade leaf dimorphism in Helianthus annuus. Canadian Journal of Botany, v. 58, p.717-30, 1980.

ESAU, K. Anatomy of seed plant. 2. ed. New York: John Wiley \& Sons, 1977.

FAILS, B.S.; LEWIS, A.J.; BARDEN, J.A. Anatomy and morphology of sun and shade-grown Ficus benjamina. Journal of American Society of Horticultural Sciences, v.107, n.5, p. 754-7, 1982.

GUTSCHICK, V.P. Reserch reviews: biotic and abiotic consequences of differences in leaf structure. New Phytologist, v.143, p.3-18, 1999.

HERMAN, P.P.J. The leaf anatomy of two Clerodendrum species (Verbenaceae). South African Journal of Botany, v.64, n.4, p.246-249, 1998.

INAMDAR, J.A. Epidermal struture and ontogeny of stomata in some Verbenaceae. Annals of Botany, v.33, p.55-66, 1969.

JORDÃO, L.R.; LOPES, V.B.; TAKAKI, M. Selection of viable seeds in Hormidium coriaceum Ldl. (Orchidaceae) by density separation. Seed Sciences \& Technology, v. 16, p. 515-519, 1988.

KAPPEL, F.; FLORE, J. A. Effect of shade on photosynthesis, specific leaf weight, leaf chlorophyll content, and morphology of young peach trees. Journal of American Society of Horticultural Sciences, v.108, n.4, p. 541-544, 1983.

KNECHT, G.N.; O'LEARY, J.W. The effect of light intensity on stomate number and density of Phaseolus vulgaris L. leaves. Bot. Gaz., v. 133, n. 2, p. 132-134, 1972.

KRAUS, J.; ARDUIN, M. Manual básico de métodos em morfologia vegetal. Seropédica: EDUR, 1997.

LAWLOR, D.W. Photosynthesis metabolism, control and physiology. Singapore: Longman, 1987.

McCONNEL, D.B.; RUGABER, P.; SHEEHAN, T.J. Light levels alter leaf anatomy of Aphelandra squarrosa 'Dania'. Journal of American Society of Horticultural Sciences, v.109, n.3, p.298-301, 1984.

Rev. Bras. Farmacogn., V. 13, n. 1, jan.-jun. 2003. 
METCALFE, C.R.; CHALK, L. Anatomy of the dicotyledons: leaves, stem, and wood in relation to taxonomy with notes on economic uses. Oxford: Clarendon, 1972.

MISSOURI BOTANICAL GARDEN. W3TROPICOS. Disponível em: <http://mobot.org/w3t/search/vasc.html>. Acesso em 02/07/2003.

NII, N.; KURIOWA, T. Anatomical changes including chloroplant structure in peach leaves under different light conditions. Journal of Horticultural Sciences, v.63, n.1, p.37-45, 1988.

PIO CORREAA, M. Dicionário de Plantas úteis do Brasil e das Exóticas Cultivadas. Rio de Janeiro: Imprensa Nacional, 1984.

RAVEN,P.H. EVERT, R.F., EICHHORN, S.E. Biologia Vegetal. Rio de Janeiro: Guanabara Koogan, 2001.

SAS INSTITUTE INC. SAS user's guide for windows environment: 6.12. Cary: SAS Institute, 1996.

SCHUQUEL, I. T. A.; MALHEIROS, A.; SARRAGIOTTO, M.H.; VIDOTTI, G.J. Iridoid glucosids from Bouchea fluminensis. Phytochemistry, v.49, n.8, p.2409-2411, 1998.

SERT, M. A. Anatomia foliar e teores de clorofila em três variedades de soja (Glycine max (L.) Merrill) e dois níveis de radiação solar. 1992. 66p. Dissertação (Mestrado em Fisiologia Vegetal) - Universidade Federal de Viçosa, Viçosa.

SYVERTSEN, J. P.; SMITH, J. R., M. L. Light acclimation in citrus leaves. I. Changes in physical characteristics, chlorophyll, and nitrogen content. Journal of American Society of Horticultural Sciences, v.109. n.6, p.807812, 1984.

VAN VOLKENBURGH, E.; DAVIES, W. J. Leaf anatomy and water relations of plants grown in controlled environments and in the field. Crop Sciences, v. 17, p. 353-358, 1977.

YANO, S.; TERASHIMA, I. Separate localization of light signal perception for sun and shade type chloroplast and palisade tissue differentiation in Chenopodium album. Plant Cell Physiology, v.42, n.12, p.1303-1310, 2001. 